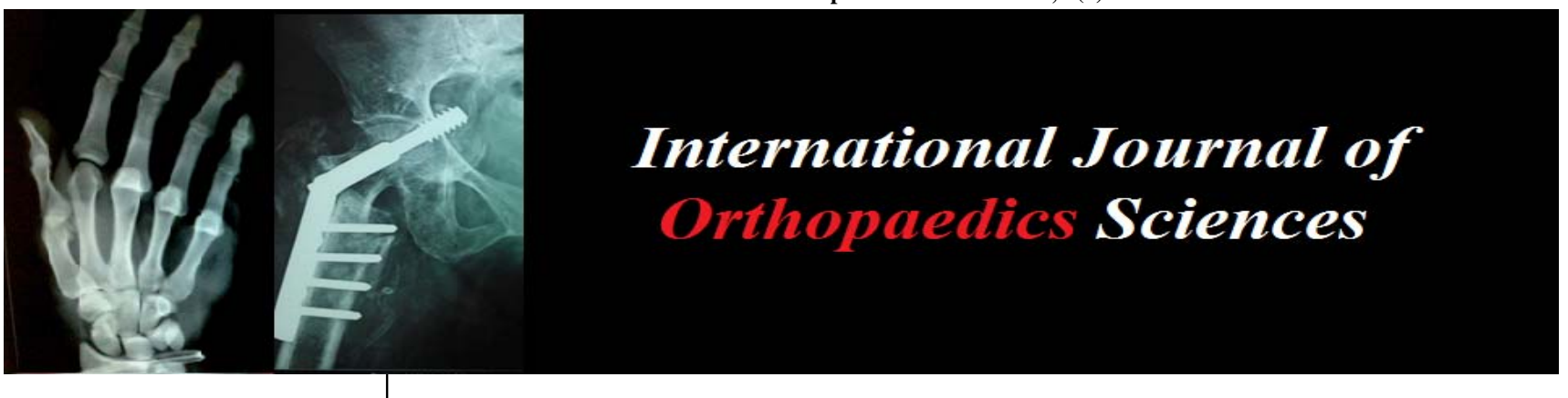

ISSN: $2395-1958$

IJOS 2018; 4(1): 316-322

(C) 2018 IJOS

www.orthopaper.com

Received: 15-11-2017

Accepted: 19-12-2017

Dr. Malleswara Rao Perumalla

Venkata Naga

Associate Professor,

Dept. of Orthopaedics, NRI

Institute of Medical Sciences,

Sangivalasa, Visakhapatnam,

Andhra Pradesh, India

Dr. Jagadeesh Babu Somesula Associate Professor,

Dept. of Orthopaedics, RVM

Institute of Medical Sciences and

Research Centre, Laxmakkapalli

(v), Mulugu (M), Siddipet Dist,

Telangana, India
Correspondence

Dr. Jagadeesh Babu Somesula Associate Professor,

Dept. of Orthopaedics, RVM Institute of Medical Sciences and Research Centre, Laxmakkapalli (v), Mulugu (M), Siddipet Dist, Telangana, India

\section{A comparative study on the fixation of fracture shaft of humerus in adults by compression plate and intramedullary interlocking nail}

\author{
Dr. Malleswara Rao Perumalla Venkata Naga and Dr. Jagadeesh Babu \\ Somesula
}

DOI: $\underline{\text { https://doi.org/10.22271/ortho.2018.v4.i1e.46 }}$

Abstract

The aim of the present study was to evaluate comparative analysis of two series in patients with diaphyseal fractures of humerus in the adults operated with dynamic compression plating and intramedullary interlock nailing with focus on their functional outcome results using DASH score and complications. The present study was conducted in the Department of Orthopaedics, Osmania Medical College and Hospital, Hyderabad, Telangana, India for a period of one year.

The study subjects consisted of $\mathrm{n}=28$ adult patients of fracture shaft of humerus with indications for surgical management. Among $\mathrm{n}=28$ subjects, $\mathrm{n}=15(53.57 \%)$ cases showed excellent results, $\mathrm{n}=8$ $(28.57 \%)$ good, $n=3(10.72 \%)$ fair and $n=2(7.14 \%)$ poor results. Among $n=15$ subjects with excellent results, $\mathrm{n}=9(60 \%)$ were of plating group and $6(46.15 \%)$ interlocking nailing. In intramedullary nailing group, $4(30.77 \%)$ patients showed good results, $2(15.38 \%)$ fair and $1(7.69 \%)$ poor results. In patients treated by plate fixation, $5(33.33 \%)$ cases showed good results, $1(6.67 \%)$ fair and $1(6.67 \%)$ poor results. For all the subjects, DASH scoring was in the range of 21-30 in 50\% subjects followed by $10-20$ in $32.14 \%, 51-60$ in $10.72 \%$ and $31-40$ in $7.14 \%$ cases. In this series, both the methods of treatment i.e. dynamic compression plating and interlocking nailing showed good functional outcome results. We prefer dynamic compression plating method as the complications are less compared to the interlocking nailing method and also with respect to pain and function of the shoulder joint.

Keywords: diaphyseal fractures, dynamic compression plate, humerus, intra-medullary interlocking nailing

\section{Introduction}

Diaphyseal fractures of the humerus and its complications are a major cause of morbidity in trauma patients. Fractures of the humeral shaft account for $20 \%$ of all the humeral fractures 1 and about $3-5 \%$ of the fractures of the human body ${ }^{[1,2]}$. With increasing road traffic accidents it is likely to be more in future.

This fracture can be treated either conservatively by using functional braces/plaster support or surgically. Non-surgical management has complications like non-union, mal-union, and persistent radial nerve deficits. Conservative treatment cannot be recommended in cases like unstable fractures (spiral/long oblique), comminuted fractures, segmental fractures, pathological fractures, fractures with delayed union or non-union. The fractures of such type require surgical intervention ${ }^{[3,4]}$.

Surgical management is recognized as the treatment of choice for most open injuries, fractures with vascular injuries, ipsilateral upper extremity segmental fractures, bilateral upper extremity fractures, radial nerve palsy, pathologic fractures, or patients who have sustained polytrauma ${ }^{[5]}$. The plate osteosunthesis and an intramedullary nailing are the two most commonly employed fixation methods, both of which carry inherent benefits and complications ${ }^{[6]}$. The dynamic compression plate (DCP) is commonly used for plating and interlocking intramedullary nail is used for nailing. Closed intramedullary nailing is widely accepted for the stabilization of the fractures of the humerus.

Several researchers compared the efficacy of compression plates with intramedullary nailing and evidenced a higher rate of complications such as shoulder pain, non-union and reoperation 
in the latter with no significant difference in functional outcome ${ }^{[7,8]}$.

Niall and his associates ${ }^{[7]}$ indicated that compression plating offers the best treatment for humeral shaft fractures that need surgical intervention. The standard management of fracture shaft humerus is with anterolateral plating or posterior plating. Plate osteosynthesis has always been a gold standard and gives good result with higher union rates.

Plate fixation when combined with open reduction and internal fixation (ORIF) method provides direct fracture visualisation, allows anatomical reduction and rigid fracture fixation but has disadvantage of excessive periosteal stripping, large incision and increased chances of infection and iatrogenic radial nerve palsy. A stable fixation allows early mobilization and thus prevents muscle atrophy, joint stiffness and osteoporosis and early return to normal activity. Closed intramedullary nailing avoids all these problems.

However, there is a growing interest in treating even simple humeral shaft fracture by dynamic compression plate (DCP) fixation or intramedullary nailing (IMN) in order to avoid union problems, allow early mobilization, reduced hospital stay and early return to work.

Therefore, the present study was undertaken to evaluate comparative analysis of two series in patients with diaphyseal fractures of humerus in the adult age group operated with dynamic compression plating and intra-medullary interlock nailing with focus on their functional outcome results using DASH score and complications.

\section{Materials and Methods}

The present study was conducted in the Department of Orthopaedics, Osmania Medical College and Hospital, Hyderabad, Telangana, India for a period of one year. The patients with an acute humeral shaft fracture in adults admitted and treated in the Orthopaedic Ward of Osmania General Hospital, Hyderabad, Telangana, India, were included in this study.

The study subjects consisted of $\mathrm{n}=28$ adult patients of fracture shaft of humerus with indications for surgical management. The inclusion criteria included all fractures of diaphysis of humerus indicated for surgical treatment, patients of age 20 years and above. Exclusion criteria included patients with open fracture of shaft humerus, polytrauma, patient not willing for surgery and patient with other injuries of the same limb, fracture of upper and lower ends of humerus, patients with pre-existing shoulder and elbow problems, pathological fractures, patients who were not available for follow up before the fracture union, patients with segmental fractures.

Ethical Committee approval was taken from the Institutional Ethical Committee Board. All the $\mathrm{n}=28$ subjects were studied by taking detailed history, clinical examination to know the nature of the fracture and followed by a routine examination consisting of an antero-posterior and a lateral radiograph of the affected arm to confirm the diagnosis. The presence or absence of radial nerve injury was recorded. The fracture was temporarily immobilized using a U-slab and arm pouch application.

All the cases $(n=28)$ of the study group were prospectively randomised into two categories viz., plating (open reduction and internal fixation with dynamic compression plating) group and intra-medullary nailing (closed reduction and internal fixation with antegrade intra-medullary interlocking nail) group for surgical management of fracture of the humeral diaphysis. The informed consent was taken from all the patients. Most of the patients were subjected to surgery within a week following admission after obtaining fitness for surgery. Delay in surgery was either due to late presentation or for seeking physician fitness for undergoing the procedure. Pre-operative planning and investigations were done and the patients were operated by open reduction and internal fixation with DCP or interlocking nailing.

\section{Case description}

This study series comprised of $n=28$ subjects with acute humeral shaft fractures. The cases were adults with age ranging from 20 to $63 \mathrm{yrs}$ with mean age being $41.59 \mathrm{yrs}$. The left side was the most commonly involved in $\mathrm{n}=20(71.43 \%)$ compared to right side in $\mathrm{n}=8(28.57 \%)$ in $5: 2$ ratio.

In this series, majority of the subjects were males $(\mathrm{n}=21)$ and $\mathrm{n}=7$ females. Road traffic accident (RTA) was the most common mode of injury $n=17(60.71 \%)$ cases followed by fall from height in $n=6(21.43 \%)$, domestic and others (Table $1)$.

\section{Site of fracture}

The fractures of humerus were classified according to the $\mathrm{AO}$ classification system into Type A (AI, A2, A3), Type B (B1, $\mathrm{B} 2$, B3), Type $\mathrm{C}(\mathrm{Cl}, \mathrm{C} 2$, and $\mathrm{C} 3) .2$ study subjects were in Type Al group (simple spiral fracture), $\mathrm{n}=4$ in $\mathrm{A} 2$ (oblique fracture with fracture angle being $\left.\geq 30^{\circ}\right), \mathrm{n}=10$ in $\mathrm{A} 3$ (transverse fracture with fracture angle $<30^{\circ}$ ), $\mathrm{n}=2$ patients in BI (spiral wedge fracture- butterfly fragment), $\mathrm{n}=7$ in B2 (bending wedge), $\mathrm{n}=1$ patient in B3 (fragmented wedge), $\mathrm{n}=$ 1 in $\mathrm{Cl}$ (complex spiral) and $\mathrm{n}=1$ patient in $\mathrm{C} 3$ (comminuted irregular) (Fig. 1).

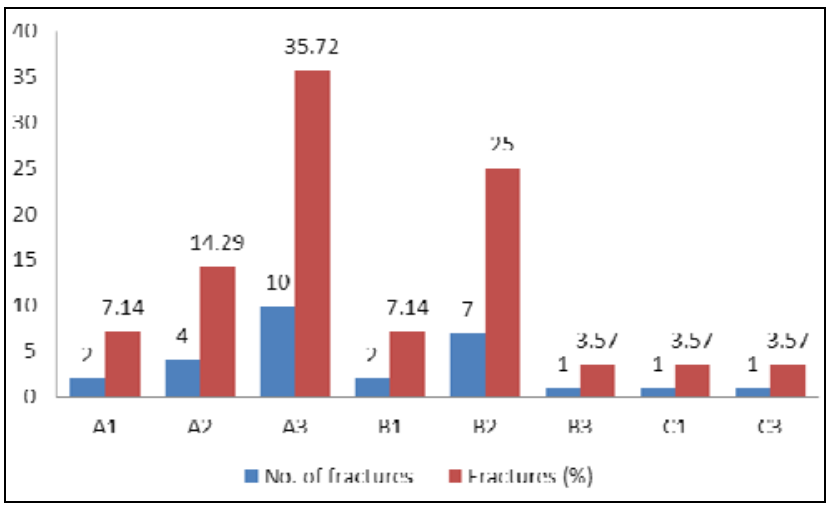

Fig 1: Percentages of fractures according to the AO classification system.

\section{Operative Technique}

In the first group, $4.5 \mathrm{~mm}$ narrow dynamic compression plate (DCP) was used, and in second group standard intramedullary interlocking nail (IMN) was used.

\section{Plate Osteosynthesis}

This is the gold standard for fixation of humeral shaft fractures. Plating is associated with high union rate, low complication rate, less hospital stay and rapid return to work. The most commonly used dynamic compression plates were used in the fractures of present series.

\section{Intra Medullary Interlocking Nail Fixation}

Closed medullary nailing of fractures of the humeral shaft is rapidly becoming the treatment of choice in multiple trauma patients, patients with osteoporotic bone, pathological fractures and segmental fractures. 
Out of $\mathrm{n}=28$ subjects, $\mathrm{n}=15(53.57 \%)$ were fixed with DCP and $n=13(46.43 \%)$ were fixed with standard interlocking nail (IMN). All $\mathrm{n}=15$ adult subjects with fractures of humeral shaft were treated surgically by open reduction and plating technique. Most of the fractures were treated with in a week after trauma except $\mathrm{n}=1$ with closed simple short oblique fracture of shaft of left humerus with left radial palsy and $\mathrm{n}=1$ patient with late presentation.

The patients were subjected to surgery by plating technique following standard Henry's antero-lateral approach in patients with fractures of the upper and middle thirds of the humerus shaft. Posterior approach was used in patients with fractures of the lower thirds of the shaft. Surgery was done within a week following admission after obtaining fitness for surgery. The patients were placed in supine position on fracture table with a pack below the scapula in anterolateral plating. All the procedures were carried out under general anaesthesia.

Through six-inch skin incision (Henry's approach), the deep fiscia was cut, the muscle biceps and brachioradialis were retracted. The radial nerve was isolated, tied and retracted. The fracture site was exposed and reduction was obtained with bone holding forceps. After adequate reduction fixation was done with a $4.5 \mathrm{~mm}$ six-holed dynamic compression plate with lag screws based on the fracture morphology. Haemostasis was secured and the wound was closed in layers. A Redivac suction drain was kept and ASD and pressure bandage was applied.

The operated limb was immobilized for initial 48 hours, following which range of motion exercises were encouraged. On the $12^{\text {th }}$ post-operative day sutures were removed and full range of motion was allowed. Patients were discharged with the arm pouch.

In one case of closed simple short oblique fracture shaft of left humerus with post- traumatic radial nerve palsy at the junction of mid and lower third. The incision was made between triceps and brachioradialis, the fracture site was exposed. This patient was operated by plating technique following Henry's postero-lateral approach. The butterfly fragment was fixed with a six holed plate and screws and the wound was closed in layers. X-ray imaging was used to verify proper plate placement.

Second group of subjects undergoing IMN, a $3 \mathrm{~cm}$ longitudinal incision was made from lateral tip of acromion, entry point was made medial to greater tuberosity. Two locking bolts proximally and two distally were inserted. Nail was locked using self-tapping screws, the proximal one from lateral to medial using Jig and Distal from anterior to posterior by a free hand technique. Only antegrade nailing was done in case of IMN group. AO type interlocking nails of 6,7 and $8 \mathrm{~mm}$ diameter were used. After surgery, all patients were given humerus U-slab in the post-operative period and elbow mobilisation with slab was started from the $3^{\text {rd }}$ or $4^{\text {th }}$ post-operative day.

Sutures were removed on the $10^{\text {th }}$ post-operative day and functional humerus bracing applied. Patients were given physiotherapy in form of strengthening exercises, static and dynamic along with shoulder pendular exercise with the humerus braces.

\section{Follow up and criteria for evaluation}

At every follow up clinical examination was done for the assessment of surgical wound healing, pain, tenderness at fracture site with free shoulder and elbow activity, stability of the fracture and clinical union. The clinical union was confirmed when the fracture site had become stable and pain free. X-rays were taken at each follow up visit to assess fracture union.

The time taken for clinical and radiological union was noted. If no clinical and radiological signs of union were observed by 16 weeks, the fracture was regarded as delayed union and absence of fracture union after 32 weeks after injury was categorized as nonunion.

The patient rehabilitation protocol was followed by shoulder, elbow, forearm and wrist exercises that were done according to the stage of fracture union and duration of time from day of surgery. Patients were advised to avoid lifting weight or putting stress on the affected limb. Patients were followed up till radiological union was confirmed.

\section{Functional outcome}

The patients in both the plating and intramedullary nailing groups were followed up every second week until radiological union was confirmed upto 34 weeks. Absence of functional pain and local tenderness at the fracture site and the presence of bridging callus in 3 of the 4 cortices seen on AP and lateral views were considered as union. The time taken for union in both these groups was recorded and the functional outcome were then compared in both the groups.

Complications such as mal-union, non-union, nerve injury, residual deformity and infections were recorded at each follow up. The functional outcome on each follow up was measured according to the "Disabilities of arm, shoulder and hand (DASH)" Questionnaire at the time of 6 months or at full recovery which ever was earlier in both these groups ${ }^{[9]}$.

The Dash scoring system is a very useful tool for measuring function of the upper limb developed by the American Academy of Orthopaedic Surgeons (AAOS) and has been validated by various researchers ${ }^{[10,11]}$.

The DASH questionnaire has thirty self-rated questions, the answers of which are graded from 1 - 5 points. The scoring varies from 0-100. A higher score indicates more disability ${ }^{[9]}$. The functional score was calculated using the formula:

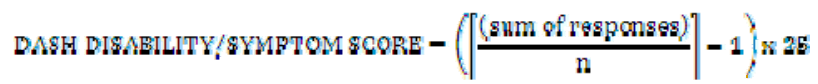

Where ' $n$ ' is the number of completed responses. The best possible score is ' 0 ' and the worst possible score is ' 100 '. The functional outcome decreases as the score increases. The result was then graded as Excellent when the score is 0 to 20 points, 21 to 40 points as Good, $41-60$ points as Fair and $\geq$ 61 as Poor. The time taken for radiological union and the functional outcome were then compared in both groups.

\section{Results and Discussion}

In plating group, anterolateral approach was followed in the patients with fractures of the upper and middle thirds of the shaft of the humerus and posterior approach in cases with fractures of the lower thirds of the shaft. Only antegrade nailing was done in case of interlocking nailing group. In the plating group, $4.5 \mathrm{~mm}$ narrow DCP was used, and in second group standard intramedullary interlocking nail was used.

Out of total $\mathrm{n}=28$ patients surgically treated, $\mathrm{n}=15$ $(53.57 \%)$ cases were operated by plate fixation and $n=13$ $(46.43 \%)$ with intra-medullary interlock nail insertion. The age of the patients in the plating group ranged from 20 to 62 yrs with mean age 40.68 yrs and in the interlocking group age range was from 26 to 63 yrs with mean age 41.59 yrs.

In this study series, according to the AO Group classification system, $\mathrm{n}=16(57.14 \%)$ patients had Type A fracture, $\mathrm{n}=10$ 
$(35.72 \%)$ patients had type $\mathrm{B}$ and $\mathrm{n}=2(7.14 \%)$ patients presented fracture type $\mathrm{C}$ (Table 1 / Fig. 1).

The left side $(\mathrm{n}=20)$ was the most commonly involved compared to right side $\mathrm{n}=8$ (Table 1$)$ in both the groups $(\mathrm{n}=$ 10 cases in each group). In both the groups, majority of the subjects were males $n=21$. In the plating group $n=12(80 \%)$ patients were male and $\mathrm{n}=3(20 \%)$ were female. In the nailing group, $\mathrm{n}=9(69.23 \%)$ cases were male and $\mathrm{n}=4$ $(30.77 \%)$ were female.

Table 1: Incidence of gender, side and fracture type in the present study subjects.

\begin{tabular}{|c|c|c|c|c|c|c|c|}
\hline \multirow{2}{*}{ Subjects } & \multicolumn{2}{|c|}{ Gender } & \multicolumn{2}{c|}{ Side } & \multicolumn{3}{c|}{ Type of fracture } \\
\cline { 2 - 8 } & Male & Female & Right & Left & Type A & Type B & Type C \\
\hline No. of cases & 21 & 7 & 8 & 20 & 16 & 10 & 2 \\
\hline Percentage (\%) & 75 & 25 & 28.57 & 71.43 & 57.14 & 35.72 & 7.14 \\
\hline
\end{tabular}

\section{Mode of injury}

Road traffic accident (RTA) was the most common mode of injury in both the groups with $n=9(60 \%)$ and $n=8(61.54 \%)$ cases in plating and IMN groups respectively followed by fall from height, domestic and others (Table 2).

Table 2: Mode of injury in the present study subjects

\begin{tabular}{|c|c|c|c|}
\hline \multirow{2}{*}{ Mode of injury } & \multicolumn{2}{|c|}{ Group } & \multirow{2}{*}{ Total } \\
\cline { 2 - 3 } & IMN & Plating & \\
\hline Domestic & $2(15.38 \%)$ & $2(13.33 \%)$ & $4(14.29 \%)$ \\
\hline Fall & $2(15.38 \%)$ & $4(26.67 \%)$ & $6(21.43 \%)$ \\
\hline RTA & $8(61.54 \%)$ & $9(60 \%)$ & $17(60.71 \%)$ \\
\hline Other & $1(7.69 \%)$ & 0 & $1(3.57 \%)$ \\
\hline Total & $13(100 \%)$ & $15(100 \%)$ & $28(100 \%)$ \\
\hline
\end{tabular}

RTA- road traffic accident

\section{Site of fracture}

The most common site of fracture in both the groups was middle third of the diaphysis with $\mathrm{n}=17(60.72 \%), \mathrm{n}=9$ $(60 \%)$ in plating group and $n=8(61.54 \%)$ in IMN group. 5 $(17.86 \%)$ fractures were in lower third, $\mathrm{n}=2(7.14 \%)$ fractures in the middle third and lower third junction, $\mathrm{n}=2$ (7.14\%) in the upper third, $\mathrm{n}=1(3.57 \%)$ between upper third and middle third junction. 1 segmental fracture extending between upper third and lower third junction in plating and IM nailing groups respectively (Table 3 ).
Table 3: Incidence of level of the fracture in the present study subjects.

\begin{tabular}{|c|c|c|c|}
\hline \multirow{2}{*}{ Site } & \multicolumn{2}{|c|}{ Group } & \multirow{2}{*}{ Total } \\
\cline { 2 - 3 } & Plating & IMN & \\
\hline $\mathrm{L} / 3$ & $3(20 \%)$ & $2(15.39 \%)$ & $5(17.86 \%)$ \\
\hline $\mathrm{M} / 3$ & $9(60 \%)$ & $8(61.54 \%)$ & $17(60.72 \%)$ \\
\hline $\mathrm{M} / 3 \mathrm{~L} / 3$ & $1(6.67 \%)$ & $1(7.69 \%)$ & $2(7.14 \%)$ \\
\hline $\mathrm{U} / 3$ & $1(6.67 \%)$ & $1(7.69 \%)$ & $2(7.14 \%)$ \\
\hline $\mathrm{U} / 3 \mathrm{~L} / 3$ & $1(6.67 \%)$ & 0 & $1(3.57 \%)$ \\
\hline $\mathrm{U} / 3 \mathrm{M} / 3$ & 0 & $1(7.69 \%)$ & $1(3.57 \%)$ \\
\hline Total & $15(100 \%)$ & $13(100 \%)$ & $28(100 \%)$ \\
\hline
\end{tabular}

L/3- lower third, M/3- middle third, U/3- upper third

The fracture union in the plating (Fig. 2A, B) group was seen at 16 weeks and in IMN (Fig 3A, B, C) group 13 weeks. 22 fractures healed within 16 weeks, $\mathrm{n}=5$ fractures healed within 6 months and $\mathrm{n}=1$ fracture with nonunion healed in 34 weeks. The average time taken for radiological union was 16 weeks and the range was 8 - 34 weeks. In the plating group, the average time taken for fracture union was 16 weeks (range $8-24$ weeks) and in the IMN group the average was 13 weeks (range $8-18$ weeks). The healing rate was relatively faster in the IMN group compared to the plating group.
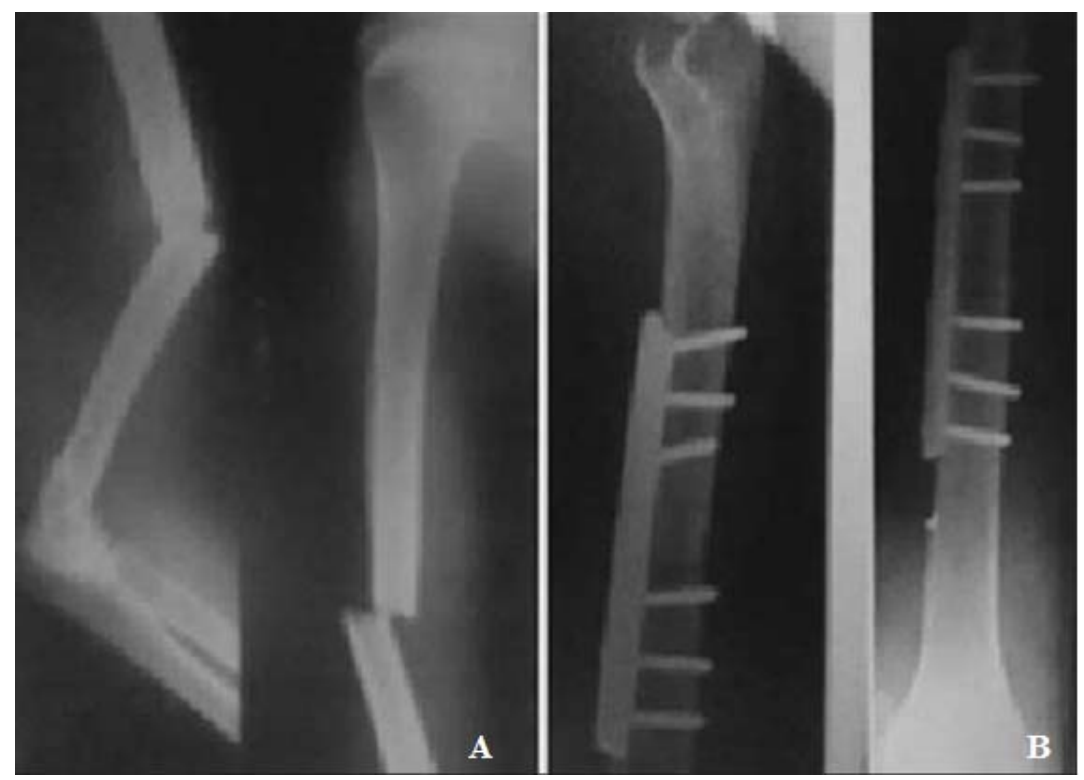

Fig 2: compression plating. A- pre-operative, B- post-operative 


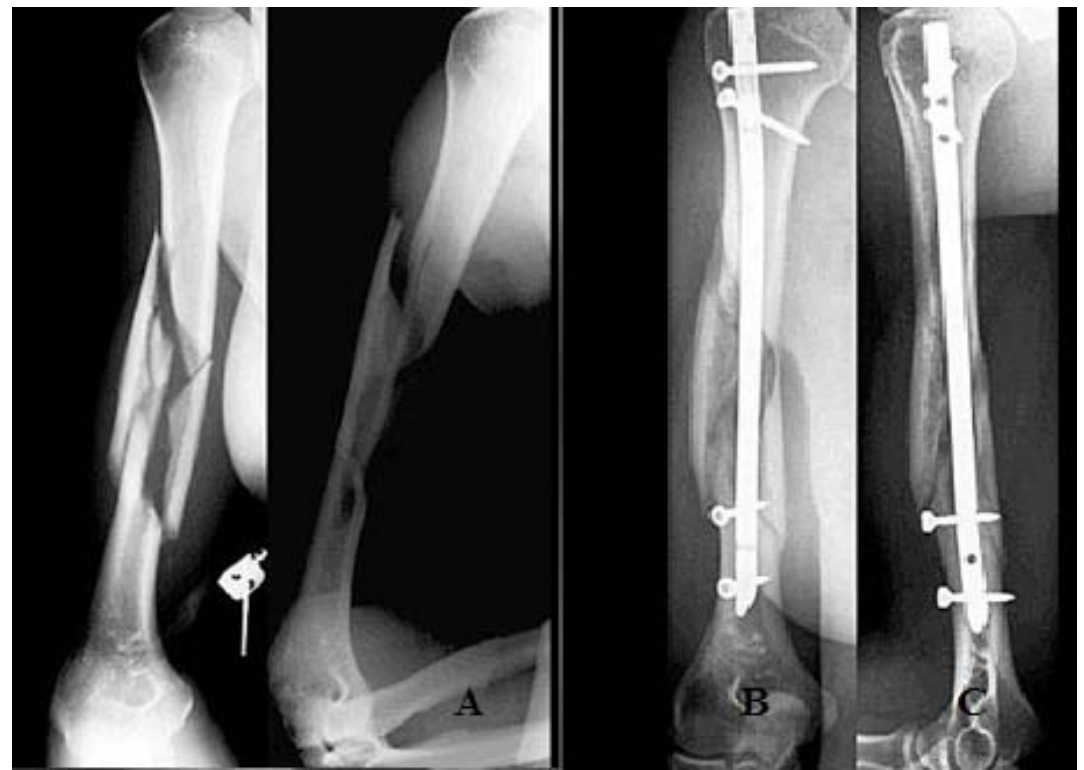

Fig 3: Intra-medullary interlocking nailing. A- pre-operative, B- immediate post-operative, C- 20 weeks post-operative

DASH scores 0 - 20 points rated as excellent, $21-40$ points as good, 41-60 points as fair and $\geq 61$ points as poor. The mean DASH score in the whole series was $36.568 / 100$ (lower the score better the function). The average DASH score in the plating group was 24.654 and in the interlocking nailing group it was 37.168 .

\section{Functional outcome results}

Among $\mathrm{n}=28$ subjects, $\mathrm{n}=15(53.57 \%)$ cases showed excellent results, $\mathrm{n}=8(28.57 \%)$ good, $\mathrm{n}=3(10.72 \%)$ fair and $\mathrm{n}=2(7.14 \%)$ showed poor results. Among the $\mathrm{n}=15$ subjects with excellent results, $n=9(60 \%)$ cases were of plating group and $n=6(46.15 \%)$ were interlocking nailing group. In the patients treated by intramedullary nailing, $\mathrm{n}=4$ $(30.77 \%)$ patients showed good results, $\mathrm{n}=2(15.38 \%)$ patients showed fair results and $n=1(7.69 \%)$ poor results. In patients treated by plate fixation, $\mathrm{n}=5(33.33 \%)$ cases showed good results, $\mathrm{n}=1(6.67 \%)$ fair and $\mathrm{n}=1(6.67 \%)$ case showed poor results.

\section{Complications}

In plating group, $12(86.67 \%)$ patients recovered completely and $\mathrm{n}=3(20 \%)$ cases had complications. There was an incidence of post-operative radial nerve palsy and fully recovered following the use of neurptrophic drugs for 3 and 6 weeks after surgery. $1(6.67 \%)$ case had non-union as the patient lifted heavy weight leading to hypertrophic non-union and resulted in poor result. $1(6.67 \%)$ patient had wound infection and recovered with antibiotics and resulted in good result (Table 4).

In the interlocking nailing group, $\mathrm{n}=8(61.54 \%)$ patients recovered satisfactorily, and $\mathrm{n}=5(38.46 \%)$ cases had complications. $2(15.39 \%)$ patients suffered additional comminution at the fracture site during nail insertion. However, later the fracture showed union and had no effect on the final outcome giving good result.

$1(7.69 \%)$ subject had superficial infection at fracture site and later the wound healed well, $\mathrm{n}=2(15.39 \%)$ patients had some residual pain in the shoulder but the patient had fair result. In $n=1$ case the patient was non-cooperative not following instructions of physiotherapy properly and the patient had severe shoulder stiffness giving poor functional result.

The IMN group had more complications (38.46\%) compared to the plating group (13.33\%). No complications like fracture displacement, plate fracture, vascular injury, infection, screw extrusion, plate breakage or screw loosening was observed in either of the groups.

Table 4: Post-operative complications in the study group subjects.

\begin{tabular}{|c|c|c|c|}
\hline \multirow{2}{*}{ Complications } & \multicolumn{2}{|c|}{ Group } & \multirow{2}{*}{ Total } \\
\cline { 2 - 3 } & ILN & Plating & \\
\hline Radial nerve injury & 0 & $1(6.67 \%)$ & $2(7.14 \%)$ \\
\hline Non union & 0 & $1(6.67 \%)$ & $1(3.57 \%)$ \\
\hline Shoulder pain & $2(15.38 \%)$ & 0 & $2(7.14 \%)$ \\
\hline Wound infection & & $1(6.67 \%)$ & \\
\hline Additional comminution & $2(15.38 \%)$ & 0 & $2(7.14 \%)$ \\
\hline Superficial infection & $1(7.69 \%)$ & 0 & $1(3.57 \%)$ \\
\hline Total & 5 & 3 & 8 \\
\hline
\end{tabular}

\section{Dash score results}

In most of the subjects functional outcome was satisfactory. Restriction of joint motion was seen in patients who didn't follow physiotherapy properly, but later joint movements were restored after 32 weeks on strict physiotherapy exercises.

For all the subjects $(\mathrm{n}=28)$, the DASH scoring was calculated after the fracture was clinically united, according to the questionnaire and the score was found in the range of 2130 in $\mathrm{n}=14(50 \%)$ subjects followed by $10-20$ in $\mathrm{n}=9$ $(32.14 \%), 51-60$ in $\mathrm{n}=3(10.72 \%)$ and $31-40$ in $\mathrm{n}=2$ $(7.14 \%)$ cases. In the patients with additional comminution and residual shoulder pain, the DASH scoring was in the range of 51 - 60 patients, however found no disability.

\section{Discussion}

Both, the compression plating and intra-medullary nailing methods are considered methods of choice of treatment in most of the humeral diaphyseal fractures. Mauch and his associates ${ }^{[12]}$ regarded compression plating as gold standard of surgical treatment yielding high union rates, less complications and early return to work. It is reported to be used effectively even in fractures with proximal and distal extensions. On the contrary, it is associated with extensive 
soft tissue handling, longer durations of surgery, periosteal stripping, high infection rate and radial nerve palsy ${ }^{[13-15]}$.

Intra-medullary nailing method provides with advantage of biological fracture healing such as minimal handling of soft tissue, preservation of fracture haematoma, and stripping of periosteum, lesser operative time and decreased blood loss ${ }^{[14,}$ 15], thus making it much preferable choice of treatment in these injured patients. However, nailing has certain disadvantages like insertion site morbidity such as impairment of shoulder movements ${ }^{[15]}$, impingement at acromion ${ }^{[14]}$ and incursion of rotator cuff $[14,15]$. Likewise, in this series we observed shoulder pain in $\mathrm{n}=2(15.35 \%)$ cases operated with IMN.

In a randomized controlled trial, Changulani et al. ${ }^{[16]}$ in their study on 47 patients reported union rates were similar in both the groups, but shorter healing time and lesser shoulder mobility in nailing and plating group respectively. In the present study, $\mathrm{n}=1$ patient had nonunion in plating group. However, we found not much dissimilarities between both the groups in terms of union time and functional outcome. Though, IMN has more complications but later recovered; is superior to plating in terms of lesser surgical time and lesser blood loss. Whereas, we observed more shoulder morbidity compared to plating.

Romens et al. ${ }^{[17]}$ reported union in $95 \%$ cases with mean time 13.7 weeks and Crates et al. ${ }^{[18]}$ reported union in $97 \%$ of fractures with mean time 3.2 months. In our study, union was achieved in all cases (except 1 case) with average period of 16 weeks.

Robinson et al. ${ }^{[19]}$ reported 3.3\%, Crates et al. ${ }^{[18]}$ reported $2.7 \%$ and $\operatorname{Lin}{ }^{[20]}$ reported $0 \%$ iatrogenic radial nerve palsy. In the plating group, the incidence of post-operative radial nerve palsy in previous studies was reported to vary between 2 $14.3 \%$, similarly we observed radial nerve palsy in $\mathrm{n}=1$ $(6.67 \%)$ in this series, later recovered fully in 16 weeks.

The most frequent problem encountered in antegrade humeral nailing has been its deleterious effect on shoulder function. Crates et al. ${ }^{[18]}$ reported $90 \%$ patients regaining full shoulder function. In the present series, residual pain in shoulder was found in $\mathrm{n}=2$ patients but restored later giving good result. It was observed that the movements and the functional ability of the shoulder regained due to the patients adherence to early rehabilitation and intensive physical exercises attributed to speedy recovery of shoulder function.

2 patients had developed shoulder pain/stiffness giving poor results in the IMN group. This study, confirms that antegrade insertion of nail can lead to problems like shoulder function and range of movement probably due to damage to the rotator cuff. The complications were more in the IMN group pertaining to poor shoulder function or pain, additional comminution and superficial infection.

Most of our findings such as period of fracture healing, union rates and functional results are comparable with earlier studies where IMN was used to treat humeral shaft fractures.

Though most surgeons agree that intramedullary nailing is the best internal fixation for femoral and tibial shaft fractures, there is no conclusive agreement about the ideal procedure for fractures of the humeral shaft. Plate osteosynthesis requires extensive soft tissue dissection with the risk of radial nerve damage ${ }^{[21]}$.

The incidence of non-union after plating in our series was in 1 $(6.67 \%)$ patient and in IMN fixation was $0 \%$. In earlier studies, the incidence of non-union after plating was reported in the range of $2-4 \%{ }^{[22,23]}$ and in the IMN fixation ranged from $0-8 \%[13,17,24]$.
In the interlocking group, there was only $1(7.69 \%)$ patient having superficial infection, which responded well to debridement and intravenous antibiotics for 3 weeks.

Though interlocking IMN is good, we still consider plate osteosynthesis is better than interlocking nailing in treating fractures of the diaphysis of the humerus.

Ante-grade nailing in the humerus has always been reported with complications of shoulder impingement or rotator cuff damage. In our study, there were only two patients who had complained of shoulder pain and stiffness, however restored later; other patients achieved painless full range of shoulder movement. Therefore, we emphasize that care has to be taken for proper insertion of nail in order to avoid damage to the rotator cuff and burying of the nail in the proximal humerus to minimize impingement.

Therefore, plate fixation is considered the gold standard for shaft fractures of humerus ${ }^{[7,8,25]}$. Anerolateral approach is widely accepted for treatment of these injuries ${ }^{[3,4,20]}$, and posterior plating is also commonly accepted.

The management of diaphyseal fractures of humerus has always been a problem as these fractures are associated with complications like nonunion, mal-union, delayed union and shortening. Operative treatment should be the choice of treatment and early mobilization is to be followed to avoid complications such as mal-union, delayed union, control rotational instability, shoulder and elbow stiffness, limb length discrepancies and poor compliance.

In 3 studies comprising of 155 patients, Bhandari et al. [6] could not establish a conclusive method. In a study on 84 such fractures treated either with plating or intra-medullary nailing, Chapman et al. ${ }^{[26]}$ concluded both as predictable methods for fracture stabilization and ultimate healing.

In this series, the operative treatment for humeral shaft fractures by plate fixation resulted in no risk of further operations and also noted that risk of reoperation may be lessened by internal fixation ${ }^{[6]}$.

\section{Conclusion}

Both intra-medullary nailing and plating are good as far as union of the fracture is concerned, but considering the functional outcome and rate of complications. According to our results we are of opinion that plating offers better result than interlocking nailing with respect to pain and function of the shoulder joint. Though, intra-medullary nailing is better over plating in terms of less operative time and lesser blood loss and less incidence of radial nerve palsy, we therefore would prefer plate fixation method, as the results are better over interlocking nailing method. The main limitation of the study is small sample size and secondly follow up period is too less to enable for effective analysis for better conclusion.

\section{References}

1. Buckholz RW, Heckman JD, Court-Brown CM, Koval KJ, Tornetta P, Wirth MA. Rockwood and Green's Fractures in Adults, 6th Edition, Lippincott Williams and Wilkins, 2006, 1.

2. Sahu RL, Ranjan R, Lal A. Fracture union in closed interlocking nail in humeral shaft fractures. Chin Med J. 2015; 128(11):1428-1432.

3. Mulier T, Seligson D, Sioen, Bergh JV, Reynaert P. Operative treatment of humeral shaft fractures. Acta Orthopaedica Belgica. 1997; 63(3):170-177.

4. Klenerman L. Fractures of the shaft of the humerus. J Bone Joint Surg Br. 1966; 48(1):105-111.

5. Brumback RJ, Bosse MJ, Poka A, Burgess AR. 
Intramedullary stabilization of humeral shaft fractures in patients with multiple trauma. J Bone Joint Surg Am. 1986; 68(7):960-969.

6. Bhandari M, Devereaux PJ, McKee MD, Schemitsch EH. Compression plating versus intramedullary nailing of humeral shaft fractures-a meta-analysis. Acta Orthop. 2006; 77(2):279-284.

7. Niall DM, O’Mahony J, McElwain JP. Plating of humeral shaft fractures-has the pendulum swung back? Injury. 2004; 35(6):580-586.

8. McCormack RG, Brien D, Buckley RE, McKee MD, Powell J, Schemitsch EH. Fixation of fractures of the shaft of the humerus by dynamic compression plate of intramedullary nail. A prospective, randomised trial. J Bone Joint Surg Br. 2000; 82(3):336-339.

9. Atroshi I, Gummesson I, Andersson B, Dahlgr E, Johannson A. The disabilities of the arm, shoulder and hand (DASH) outcome questionnaire. Acta Orthop Scand. 2000; 71(6):613-618.

10. Atroshi I, Gummesson I, Andersson B, Dahlgr E, Johannson A. The disabilities of the arm, shoulder and hand (DASH) outcome questionnaire. Acta Orthop Scand, BMC Musculoskelet Disord. 2006; 7:44.

11. Michael MW, Tracy 1, Winston, Vucy, Schemitsch. Functional Outcome Following Surgical Treatment of Intra-Articular Distal Humeral Fractures Through a Posterior Approach. 82-A(12):170111707.

12. Mauch J, Renner N, Rikli D. [Intramedullary nailing of humeral shaft fractures - initial experiences with an unreamed humerus nail]. Swiss surgery $=$ Schweizer Chirurgie $=$ Chirurgiesuisse $=$ Chirurgiasvizzera. 1999; 6(6):299-303.

13. Ingman AM, Waters DA. Locked intramedullary nailing of humeral shaft fractures. Implant design, surgical technique, and clinical results. J Bone \& Joint Surg, British. 1994; 76(1):23-29.

14. Watanabe RS. Intramedullary fixation of complicated fractures of the humeral shaft. Clinical orthopaedics and related research. 1993; 292:255-263.

15. Hall RF, Pankovich AM. Ender nailing of acute fractures of the humerus. A study of closed fixation by intramedullary nails without reaming. J Bone Joint Surg Am. 1987; 69(4):558-567.

16. Changulani M, Jain UK, Keswani T. Comparison of the use of the humerus intramedullary nail and dynamic compression plate for the management of diaphyseal fractures of the humerus. A randomized controlled study. International orthopaedics. 2007; 31(3):391-395.

17. Rommens PM, Verbrungen J, Bros PL. Retrograde locked nailing of humeral shaft fractures. J. Bone Joint Surg (Br). 1995; 77B:84-89.

18. Crates J, Whittle AP. Antegrade interlocking Nailing of acute Humeral Shaft Fractures. J Clinic Orthop. 1998; 350:40-50.

19. Robinson CM, Bell KM, Court-Brown CM, Mc Queen MM. Locked nailing of humeral shaft fractures: experience in Edinburgh over a 2 year period. $\mathrm{J}$ Bone Joint Surg. 1992; 74B:558-562.

20. Lin J. Treatment of humeral shaft fractures with humeral locked nail \&comparision with plate fixation. J Trauma. 1998; 44(5):859-864.

21. Ruedi T, Moshfeigh A, Pfieffer K, Allgower M. Fresh fractures of the shaft of the humerus. -Conservative or operative treatment? Reconstion Surg and trauma. 1974; 14:65-74.
22. Heim D, Herkert F, Hess P, Regazzoni P. Surgical treatment of humeral shaft fractures: the Basel experience. J Trauma. 1993; 35:226-232.

23. Bell MJ, Beauchamp, Kellam JK, Mc Murtry. The Results of Plating Humeral Shaft Fractures in Patients with Multiple Injuries, The Sunny Brook Experience. JBJS Am. 1985; 67:293-296.

24. Hems TE, Bhullar TP. Interlocking nailing of humeral shaft fractures: the Oxford experience 1991-1994. Injury. 1996; 27:485-489.

25. Muller ME, Nazarian S, Koch P, Schatzker J. The comprehensive classification of fractures of the long bones. New York, Berlin Heidelberg, Springer. 1990.

26. Chapman JR, Henley MB, Agel J, Benca PJ. Randomized prospective study of humeral shaft fracture fixation: intramedullary nails versus plates. J Orthopaedic Trauma. 2000; 14(3):162-166. 